\title{
Comportamento Aleatório: Algumas Considerações
}

\author{
Lourenço de Souza Barba ${ }^{1}$ \\ Universidade de São Paulo
}

\begin{abstract}
RESUMO - Este estudo defende que o comportamento aleatório pode tornar-se legítimo objeto de estudo de uma ciência do comportamento. Analisamos inicialmente algumas considerações que B. F. Skinner formulou sobre o comportamento aleatório em suas Contingências do Reforço. Segundo Skinner (1969/1975), o comportamento aleatório "não apresenta interesse como processo de comportamento". Apresentamos uma rigorosa definição de "comportamento aleatório". Sustentamos que o comportamento aleatório pode constituir objeto de análise funcional, examinando alguns estudos empíricos que se têm conduzido sobre o comportamento aleatório. Apresentamos ainda algumas dificuldades empíricas e teóricas que podem afetar as investigações nessa área. Concluímos que o comportamento aleatório é um fascinante e importante tópico para uma completa ciência do comportamento.
\end{abstract}

Palavras-chave: comportamento aleatório; variabilidade comportamental; seleção dependente da freqüência; esquema de reforço de percentil.

\section{Random Behavior}

\begin{abstract}
In this paper we claim that random behavior may become a legitimate subject matter of a behavioral science. We analyze initially some considerations B. F. Skinner has formulated concerning random behavior, in his Contingencies of Reinforcement. According to Skinner (1969/1975), random behavior "is of no interest as a behavioral process". We present a rigorous definition of "random behavior". We claim that random behavior, so defined, may be functionally analyzed, by examining some empirical investigations concerning random behavior that have been conducted. We also present some empirical and theoretical difficulties that can affect investigations in this area. We conclude that random behavior is a fascinating and important topic to a complete science of behavior.
\end{abstract}

Key words: random behavior; behavioral variability; frequency-dependent selection; percentile - reinforcement schedule.

Em seu livro Contingências do Reforço, pede-nos Skinner (1969/1975) que suponhamos o seguinte cenário: pediramnos que apanhássemos a mala de um amigo no bagageiro de um aeroporto. Nunca vimos a mala. Somente temos um cartão que traz o número da mala a ser encontrada. Centenas de malas são colocadas à nossa frente, num porta malas rotativo. Tomando uma mala por vez, teríamos de confrontar o número de cada uma delas com o número que trazíamos no cartão. Se as malas não diferissem muito na sua aparência, seria possível que viéssemos a retirar a mesma mala mais de uma vez. Uma estratégia eficaz seria, segundo Skinner, marcar com um giz todas as malas já examinadas, evitando que a mesma mala fosse retirada mais de uma vez e reduzindo rapidamente o número das que esperavam por serem verificadas. Diz Skinner:

Por simples que pareça, este método de resolver o problema tem algumas características notáveis. A simples verificação ao acaso, até achar a mala certa, não apresenta interesse como processo de comportamento; o número de verificações requeridas para resolver o problema não é uma dimensão do comportamento. (p. 30)

Que significaria "verificação ao acaso"? Por que esse procedimento não apresenta interesse como processo de

1 Endereço: Rua Braseliza Alves de Carvalho,522. São Paulo - SP. CEP 02510 - 030, e - mail: loub@uol.com.br comportamento? Em que consistiria exatamente essa estratégia de verificação?

Retirar as malas ao acaso é também comportamento. Parece-nos, portanto, que seria pertinente examinar teórica e empiricamente esse padrão comportamental. O tema apresenta, parece-nos, alguma relevância teórica e, talvez, prática. Um primeiro passo seria o de formular, em termos rigorosos, o que viria a ser, exatamente, o retirar as malas "ao acaso". É o que faremos em seguida, apontando certas propriedades que podem definir esse comportamento.

Na situação que descreve Skinner, devíamos identificar uma única mala correta. Suponha-se, no entanto, que alterássemos a tarefa da forma seguinte: seriam colocadas, à nossa frente, seis malas perfeitamente idênticas, na sua forma exterior. Cada mala teria estampado, em seu interior, um número inteiro: mala 1 , mala 2 , mala 3 , mala 4 , mala 5 e mala 6. Deveríamos apanhar uma única mala por vez e verificar que número ela continha. O número seria anotado à parte. Deveríamos, em seguida, devolver a mala ao conjunto, sem que lhe pudéssemos imprimir qualquer marca. A cada nova retirada, as malas seriam reagrupadas de maneira aleatória, sem que pudéssemos presenciar o arranjo (suponha-se, por hipótese, que todas as malas fossem colocadas dentro de um grande recipiente e, em seguida, fossem dali retiradas ao acaso, à semelhança do que ocorre em um sorteio em que pequenos pedaços de papel idênticos são retirados de um recipiente opaco). As seis malas nos seriam, em seguida, apresentadas novamente. 
Ao retirar as malas seguidas vezes, iríamos compondo uma série numérica em que entrariam os caracteres 1, 2, 3, 4,5 e 6 . Nossa tarefa completa seria a de retirar, um grande número de vezes, digamos 10.000 , a mala 3 .

Havendo retirado 10.000 vezes a mala 3, teríamos constituído uma grande série numérica (algo como 6, 3, 1, 2, 5, $4,5,1,3 \ldots)$. Se viéssemos, durante todo o tempo, retirando as malas ao acaso (isto é, se não houvesse, em qualquer ocasião, qualquer fator que nos induzisse a tirar preferencialmente qualquer das seis malas), em que proporção esperaríamos contar o caracter 3 nessa grande série? Deveríamos encontrá-lo na proporção aproximada de 1/6 (nossa série numérica devia, portanto, conter aproximadamente 60.000 caracteres, na altura em que houvéssemos já retirado 10.000 vezes a mala 3). E não apenas o caracter 3, mas ainda todos os demais caracteres $(1,2,4,5$ e 6) deveriam compor a série na proporção aproximada de 1/6.

Mas não somente as proporções dos caracteres individuais apresentariam essa propriedade. Se retirássemos as malas ao acaso, muito dificilmente comporíamos uma série invariável como esta: 6, 5, 4, 3, 2, 1, 6, 5, 4, 3, 2, 1, 6, 5, $4,3,2,1 \ldots$, em que os seis caracteres figurariam na proporção de 1/6. Seria igualmente improvável que compuséssemos qualquer outra série que repetisse periodicamente um mesmo padrão invariável. Quer isto dizer que também os arranjos de caracteres (pares de caracteres, tercetos de caracteres, quartetos de caracteres etc...) deveriam encontrar-se em proporções aproximadamente iguais em grandes séries compostas ao acaso (Attneave, 1969). A essas séries chamaremos séries "casuais" ou "aleatórias". Note-se que "aleatoriedade" não se deve confundir com "variação": A série regular $6,5,4,3,2,1,6,5,4,3,2,1,6,5,4,3,2,1 \ldots$ é variada, em algum sentido, pois exibe mais de um caracter, mas não é aleatória. A aleatoriedade implica variação, mas nem toda variação é aleatória.

Podemos formalizar rigorosamente o conceito de "série aleatória" nos termos que seguem. Recorramos a uma série de eventos que, segundo definição aceita em teoria das probabilidades (Attneave, 1969), constituem exemplo de eventos aleatórios ou casuais. Os sucessivos lances de um dado comum prestam-se a ilustrar o caso. Deles podemos extrair uma sequiência de eventos discretos, correspondentes, cada um deles, à face do dado que se encontrava voltada ao alto, ao final de cada lance (por exemplo, uma seqüência como ...2, 3, 6, 1, 2, 4, 5...). A cada um dos diferentes possíveis eventos discretos denominaremos caracter. São seis, portanto, os caracteres constituintes da nossa seqüência, qualquer que seja a sua extensão (caracter 1 , caracter 2 , caracter 3 , caracter 4 , caracter 5 , caracter 6 ). Cada lance do dado corresponde a um evento. Assim, a seqüência ...2, 3, 6, 1, $2,4,5 \ldots$ compreende sete eventos. Nessas condições, se for honesto o dado utilizado, isto é, se forem iguais a 1/6 as probabilidades de ocorrência de qualquer caracter particular, esperaríamos encontrar, em uma seqüência bastante longa uma proporção aproximadamente igual a 1/6 de cada um dos seis caracteres. E, mais que isso, deveríamos observar, também, nessa sequiência, proporções idênticas de to- dos os arranjos completos (Ac) constituídos a partir desses seis caracteres. Ou seja, a seqüência deveria conter, em iguais proporções, os 36 pares constituíveis a partir dos seis caracteres, tomados dois a dois (36 é o número de arranjos completos de seis elementos dois a dois, Ac 6,2=6 $6^{2}=36$ ). Assim também os $6^{3}$ (Ac 6,3) tercetos possíveis deveriam figurar em frações idênticas $\left(1 / 6^{3}\right)$. A sequiência $2,4,3,1$, $2,5,6,3$, por exemplo, encerra oito eventos e contém os caracteres $1,4,5$ e 6 na proporção de $1 / 8$. Os caracteres 2 e 3 figuram na proporção de $2 / 8$. Os pares $2-4,4-3,3-1,1-2$, 2-5, 5-6 e 6-3 encontram-se em frações de $1 / 7$, cada um deles (sete é o número total de pares contáveis na sequiência). Os tercetos 2-4-3, 4-3-1, 3-1-2, 1-2-5, 2-5-6 e 5-6-3 apresentam-se na freqüência de $1 / 6$ cada um deles (seis é o número total de tercetos contáveis na seqüência). $\mathrm{O}$ mesmo se diz de todos os demais arranjos possíveis. Isto é, proporções similares deveriam constar, nessa sequiência, de quartetos, quintetos, sextetos, ..., $n$-tetos, constituídos a partir dos seis caracteres. De uma sequiência nessas condições, diremos que é aleatória.

No caso das seis malas, que atrás deixamos descrito, supusemos que as malas eram perfeitamente idênticas no seu aspecto externo e que eram reagrupadas, depois de cada retirada. Suponha-se, no entanto, que as malas não fossem reagrupadas e não fossem idênticas, diferindo claramente entre si, todas as seis, na forma ou na cor, ou em qualquer outra propriedade externa. Suponha-se, ainda, que pudéssemos apresentar, ao indivíduo que as retirava, conseqüências específicas após a retirada de cada uma delas separadamente. Teria ele, ainda aqui, de retirar apenas uma mala por vez, anotar seu número e, em seguida, restituí-la à exata posição que ocupava no conjunto de malas. À medida que as fosse retirando, uma série numérica se iria constituindo. Uma pertinente questão de engenharia do comportamento poderia então formular-se nestes termos: Poderíamos levar o indivíduo a compor uma série aleatória de números, reforçando, ou não, a retirada de cada mala separadamente? "Reforçar" denota aqui somente o procedimento de dispor consequiências específicas para a retirada de cada mala. Seria possível, em outras palavras, fazer com que o organismo, ao retirar grande número de malas, produzisse uma sequiência aleatória delas, manipulando apenas as conseqüências que seguissem as retiradas de determinadas malas? Ou, em termos mais gerais, seria possível levar um organismo a gerar uma seqüência aleatória de caracteres, manipulando somente as conseqüências de certas respostas que emitisse? O procedimento de reforçar diferencialmente poderia, por si só, engendrar ou manter a emissão de sequiências aleatórias? Essa é a questão a que nos dedicaremos em seguida.

Falamos anteriormente em seis malas. Claro esteja, no entanto, que as malas poderiam ser em maior ou menor número. Duas malas constituiriam o número mínimo, para que pudéssemos falar em série aleatória. Nos estudos empíricos de que nos ocuparemos em seguida, eram somente duas as opções: duas barras de pressionar ou dois discos que se instalaram em caixas experimentais. 
Conceituar "comportamento operante" implica distinguir duas classes de resposta: a classe de respostas que produz conseqüências diferenciais e a classe de respostas cuja frequiência se eleva ou se mantém em razão das ditas conseqüências:

As duas classes não precisam corresponder exatamente. De fato, o grau de correspondência entre (1) o comportamento que é reforçado e o (2) comportamento gerado por esse reforço é uma dimensão fundamental de qualquer classe de respostas reforçadas. O comportamento que é reforçado é chamado de (1) classe descritiva ou nominal; o comportamento gerado pelo reforço é chamado de (2) classe funcional (Catania, 1998/1999, p. 135)

Veremos que essa distinção é particularmente útil aqui, quando examinarmos as pesquisas empíricas que buscaram levar à emissão de seqüências aleatórias. Esses estudos experimentais definiram diferentes classes descritivas.

À luz dessa distinção, podemos ainda reformular nossa questão: Há uma ou mais classes descritivas a que possa corresponder a classe funcional "série aleatória"? Em caso afirmativo, quais seriam elas? Ou ainda, que contingência (referimo-nos aqui apenas às contingências de dois termos: $\mathrm{R}-\mathrm{S}$ ) deveria vigorar para que fossem produzidas séries aleatórias? Examinaremos em seguida alguns estudos empíricos que buscaram responder a essa questão.

É conveniente que, antes de irmos aos estudos empíricos, tenhamos clara uma dificuldade metodológica que se apresenta a todos quantos se disponham a investigar empiricamente essa questão. Do que acima ficou estabelecido, decorre que, em estudos dessa espécie, devem constituir variáveis dependentes não somente as freqüências em que se vão encontrar os caracteres isolados, mas também as freqüências em que hão de figurar os pares de caracteres, os tercetos, os quartetos, os quintetos, e assim por diante. As sequiências de que dispõem os experimentadores contêm, no entanto, um número finito de eventos. Nascem daí duas dificuldades: primeiramente, a análise há de interromperse necessariamente em algum nível de arranjo dos caracteres; em segundo lugar, espera-se, de uma sequiência aleatória, que as frequiências em que se apresentam os diferentes arranjos, dentro de um mesmo nível, sejam aproximadamente iguais, somente se a sequiência estiver constituída por um grande número de eventos. Se, de uma seqüência aleatória de lançamento de dados, composta de várias centenas de eventos, extraíssemos um pequeno segmento em que entrassem apenas dez eventos, e medíssemos as frequiências em que apareciam os seis caracteres, muito provavelmente não as encontraríamos todas próximas de 1/6. De forma análoga, seria improvável encontrarmos todos os pares de caracteres na proporção de $1 / 36$, se nosso segmento contivesse apenas 50 eventos, por exemplo. Assim, as grandes discrepâncias que se verificam entre as freqüências dos diversos caracteres, ou arranjos deles, são indicativos de não aleatoriedade, desde que a seqüência em questão contenha um número suficientemente grande eventos, cujo valor exato depende da quantidade de caracteres a consti- tuí-la e do nível em se tomam os arranjos. Vamos, pois, aos trabalhos empíricos. Reunimos alguns estudos que podem, supomos, introduzir o leitor ao tema, dando-lhe idéia dos rumos que têm tomado as pesquisas nessa área de estudo.

\section{Esquema $L A G$}

Page e Neuringer (1985) investigaram os efeitos do reforçamento diferencial sobre a produção de séries aleatórias de sequiências. Seu procedimento exato foi o seguinte: pombos eram colocados diante de duas chaves de respostas, dispostas uma ao lado da outra, dentro de um caixa experimental. As respostas a cada uma das chaves eram registradas separadamente. Em ambas, o procedimento de operante restrito foi adotado: a oportunidade de responder era sinalizada e marcava o início de uma tentativa. Uma série de oito bicadas consecutivas, a qualquer uma das chaves, constituía uma sequiência ou tentativa completa, a que se seguia a apresentação do reforço ou um time-out.

Na primeira etapa do experimento, a apresentação do reforço era contingente a que os animais emitissem sequiências que diferissem das $n$ últimas seqüências emitidas (procedimento $l a g-n$ ). $\mathrm{O}$ conjunto de quatro respostas consecutivas à chave esquerda (EEEE), seguidas de quatro respostas consecutivas chave direita (DDDD) constituía a sequiência comportamental EEEEDDDD, que diferia, por exemplo, da seqüência EEEEDDDE. Duas sequiências diferiam, se apresentassem diferentes quantidades de elementos $\mathrm{E}$ e $\mathrm{D}$ e /ou se os apresentassem em diferentes ordens. No procedimento lag-15, por exemplo, uma seqüência era seguida de reforço, se, e somente se, diferisse das últimas 15 seqüências, emitidas nas últimas 15 tentativas.

$\mathrm{O}$ valor de $n$ foi manipulado, assumindo progressivamente os valores $5,10,15,25$ e 50. Três índices estatísti$\cos$, oriundos da teoria da informação, constituíram as principais variáveis dependentes. Os três exprimiam o grau de aleatoriedade em que foram emitidas: As respostas individuais, E ou D, (índice U1); Os pares de respostas consecutivas, EE, ED, DE, DD, (índice U2); Os tercetos de respostas consecutivas, EEE, EED, EDE, EDD, DDD, DDE, DED, DEE, (índice U3). Computaram-se os índices para cada uma das sessões experimentais. Tomando-se sempre, por referência, o conjunto de respostas emitidas em uma única sessão, ocorria que o índice U1 assumia seu valor máximo $(1,0)$, se as respostas individuais houvessem sido emitidas em proporções idênticas; o índice U2 assumia seu valor máximo $(1,0)$, se os pares de respostas consecutivas houvessem sido emitidos em proporções idênticas; o índice U3 assumia seu valor máximo $(1,0)$, se os tercetos de respostas consecutivas houvessem sido emitidos em proporções idênticas. O valor mínimo $(0,0)$ era atingido, se apenas uma resposta, no caso de U1, ou apenas um par de respostas consecutivas, no caso de $\mathrm{U} 2$, ou apenas um terceto de respostas consecutivas, no caso de U3, fossem emitidos em uma sessão. Page e Neuringer (1985) chamaram "variabilidade" ao montante de aleatoriedade que mediram. Ou seja, chamaram "variabilidade" aos índices U que obtiveram. 


\section{S. Barba}

Os três índices assumiram valores progressivamente maiores, à medida que se ia elevando o valor de $n$. Atingiram seu ponto mais elevado, próximo de 1,0, quando a $n$ foi atribuído o valor 25. Apresentaram, em seguida, uma pequena queda, quando o valor de $n$ subiu a 50 .

Estaria, assim, comprovado que o reforçamento diferencial da classe descritiva "ser diferente das $n$ últimas sequiências emitidas" (ou seja, a contingência lag $-n$ ) foi o responsável direto pela aleatoriedade que obtiveram? Ao menos uma objeção poderia opor-se a essa conclusão. $\mathrm{O}$ esquema $l a g-n$ exigia que as sequiências de respostas diferissem das $n$ últimas seqüências emitidas, sem o que não seriam seguidas de apresentação de reforço. Ao menos parte das seqüências emitidas pelos animais não atendia a essas exigências, uma vez que a porcentagem de tentativas reforçadas esteve sempre abaixo de $100 \%$, havendo uma queda progressiva desse percentual, à medida que se elevava o valor atribuído a $n$. Houve, portanto, em todos os casos, sequiências de respostas não seguidas por apresentação de reforços.

Há, por outro lado, estudos que demonstram a relação estreita que parece vigorar entre regime intermitente de apresentação de reforços e distribuição de respostas por dois ou mais manipulanda, situados em diferentes regiões do espaço. São eles: Antonitis (1951), Ferraro e Branch (1968), Eckerman e Lanson (1969) e Boren, Moerschbaecher e Whyte (1978). Esses estudos indicaram que maiores graus de intermitência levavam a maior distribuição de respostas.

Dessa forma, poderia formular-se, em oposição aos resultados de Page e Neuringer (1985), a seguinte objeção: a maior aleatoriedade que obtiveram, ao elevarem o valor de $n$, no procedimento $l a g-n$, deveu-se à menor freqüência de reforços a que muito provavelmente submeteram seus animais, à medida que elevavam o valor de $n$. Isto é, a aleatoriedade obtida poderia não ser função do reforçamento diferencial da emissão de sequiências diferentes. O mesmo nível de aleatoriedade poderia obter-se, talvez, pela simples exposição dos animais àqueles níveis decrescentes de frequiência de reforçamento.

Page e Neuringer (1985) adotaram um procedimento com que procuraram contornar essa dificuldade. Numa segunda etapa de seu experimento (experimento 5), os animais foram expostos a um esquema que requeria igualmente a emissão de oito bicadas por sequiência, mas em que a apresentação dos reforços seguia, pari passu, a distribuição de reforços obtida na contingência lag - $n$, qualquer que fosse a sequiência particular emitida na atual oportunidade (procedimento yoked). Assim, uma sessão yoked apresentava uma distribuição previamente estabelecida de reforços por tentativa. Isto é, seria reproduzida, na sessão yoked, a exata distribuição obtida pelo mesmo sujeito (selfyoked), numa sessão anterior em que vigorava a contingência lag $-n$ (sessão referência). Assim, se um sujeito houvesse recebido seus três primeiros reforços nas tentativas 1 , 5 e 7, no esquema lag $-n$ (sessão referência), esse mesmo sujeito, receberia, no esquema yoked, seus três primeiros reforços nas tentativas 1,5 e 7 , quaisquer que fossem as seqüências de respostas discretas emitidas por ele nessas tentativas. Os animais foram submetidos a sessões yoked em que se reproduziam as distribuições de reforços obtidas em sessões lag - 50. Depois de atingir um patamar estável o desempenho nesse esquema, passou-se a uma nova série de sessões $l a g-50$, a que se seguiram posteriormente, tomando-as por referência, novas sessões yoked.

Esse esquema permitiu, segundo seus autores, isolar a variabilidade mantida exclusivamente pelo esquema de reforçamento $(l a g-n)$ da variabilidade resultante da intermitência de reforçamento. De fato, os níveis de aleatoriedade, medidos pelos índices $\mathrm{U}$, atingiram, nas sessões finais em que vigorava o esquema yoked, valores significativamente menores que os obtidos nas sessões em que vigorava o procedimento lag $-n$. Isto é, o reforçamento intermitente não manteve, por si só, os altos índices de aleatoriedade alcançados nos esquemas lag $-n$.

Esses resultados exigem, contudo, algumas considerações adicionais acerca das peculiaridades do delineamento yoked. O esquema yoked apresenta características de um esquema de razão variável (Page e Neuringer o denominaram yoked-VR). Uma importante característica dos esquemas de razão consiste em que, neles, a taxa de reforçamento (número de reforços obtidos / intervalo fixo de tempo) é função direta da taxa de respostas (Catania, 1998/1999). Segue-se, pois, que as taxas de reforçamento verificadas no esquema yoked são função direta do quociente número de seqüencias executadas / intervalo fixo de tempo.

Ocorre que a emissão de uma sequiência é, presumivelmente, tanto mais rápida, quanto menor é o número de vezes que o animal passe de uma a outra chave, porquanto a própria resposta de passar de uma a outra chave consome um certo intervalo de tempo. No esquema yoked, portanto, as mais elevadas taxas de reforçamento são obtidas pelo animal que emite exclusivamente seqüências de um único componente (como EEEEEEEE ou DDDDDDDD, no experimento de Page \& Neuringer), uma vez que a contingência não impõe qualquer restrição quanto à composição particular da sequiência emitida.

O comportamento de não passar de uma a outra chave, ou de o fazer menos freqüentemente, pode ter sido o efeito desse reforçamento diferencial. É possível, portanto, que o delineamento yoked-VR, ao dispensar maiores taxas de reforçamento aos animais que emitissem respostas sobre uma única chave, tenha reforçado diferencialmente um comportamento incompatível com a emissão de sequiências aleatória de respostas. Essa tese encontra alguma sustentação na literatura. Vejamos qual seja ela.

Já nos referimos a alguns estudos em que se demonstrou a provável relação que parece vigorar entre regime intermitente de apresentação de reforços e distribuição de respostas por dois ou mais manipulanda, situados em diferentes regiões do espaço. Note-se, contudo, que esses estudos investigaram os efeitos do estabelecimento de alguns esquemas de intervalo sobre a distribuição espacial das respostas. Em todos eles, tomou-se, por linha-de-base, a distribuição observada em esquemas de reforçamento contí- 
nuo. Somente um dos procedimentos, executado por Boren e cols. (1978), fugiu a essa regra. Em uma de suas manipulações, esses pesquisadores mediram a distribuição das respostas, por seis barras alinhadas horizontalmente, emitidas por macacos rhesus. Instauraram primeiramente um esquema de reforçamento contínuo, a que se sucedeu um esquema de razão fixa. Verificaram os pesquisadores que a distribuição das respostas pelas seis barras diminuiu, à medida que se elevavam os valores nominais dos esquemas FR (isto é, à medida que se tornavam mais intermitentes as apresentações de reforços). É preciso concluir, pois, que a intermitência na apresentação de reforços pode conduzir a maior ou menor distribuição das respostas pelos manipulanda, a depender do esquema em que ocorre a intermitência, se de intervalo ou razão.

Page e Neuringer (1985), ao instituírem o esquema yoked - VR, parecem não ter considerado essa circunstância. A completa demonstração de que a aleatoriedade que obtiveram devia-se exclusivamente ao esquema de reforçamento diferencial (procedimento lag $-n$ ), e não à mera intermitência de reforços, exigiria que uma segunda espécie de procedimento yoked fosse também instaurada (talvez um yoked - VI). Seria necessário verificar se também a intermitência na apresentação de reforços, em um esquema de intervalo, não produziria, ou ao menos manteria, altos níveis de aleatoriedade.

\section{Percentis}

Vimos que Page e Neuringer (1985) manipularam o valor de $n$, no esquema lag $-n$. Pombos foram expostos a esquemas lag $-n$ em que os valores de $n$ elevavam-se progressivamente. Verificaram aqueles pesquisadores, como vimos, que os índices de variabilidade elevavam-se, à medida que se elevava o valor de $n$. Note-se, entretanto, que, ao manipular $n$, os pesquisadores presumivelmente alteraram também a frequiência de reforçamento que vinham obtendo os animais, ao passarem de um esquema menos exigente a um esquema mais exigente. Logo, os incrementos sucessivos nos níveis de variabilidade eram provavelmente precedidos de quedas sistemáticas nas freqüências de reforçamento a que se vinham submetendo os pombos. Parte da variabilidade obtida ao introduzir-se um esquema mais exigente poderia dever-se a essas flutuações nos níveis de freqüência de reforçamento, e não à vigência do esquema lag $-n$. Machado (1989) buscou controlar os efeitos dessa variável.

Machado (1989) submeteu pombos a uma contingência que requeria dos animais a emissão de quatro bicadas consecutivas (à chave direita ou esquerda), ao final das quais poderia apresentar-se o reforço. Houve, também nesse caso, a exigência de que a seqüência emitida diferisse ao menos das $n$ últimas seqüências emitidas. Nesse procedimento, porém, o valor de $n$ foi ajustado durante o experimento, após a emissão de toda sequiência completa, de modo a tornar praticamente constante a probabilidade de emissão de uma seqüência reforçável. Com esse artifício pretendeu Machado controlar o efeito da variável intermitência de reforçamento, à semelhança do que pretenderam Page e Neuringer (1985) com o procedimento yoked. O procedimento que tornou possível esse controle fundamentou-se em três conceitos que apresentamos em seguida.

O primeiro e mais importante deles é o tempo de recorrência (TR). O tempo de recorrência corresponde ao número de sequiências que separam a ocorrência da sequiência $\mathrm{S}$, num instante $t$, da última ocorrência de $\mathrm{S}$ num instante anterior a $t$. A cada uma das seqüências emitidas na contingência lag $-n$, por exemplo, pode ser associado um valor de TR. Assim, por exemplo, no conjunto de seqüências EEEE-(1), DEDD-(2), DEDE-(3), EEEE-(4), DEDE-(5), DEDE-(6), a seqüência 4 apresenta um valor de TR igual a 2 , enquanto a seqüência 5 apresenta um valor de TR igual a 1 e a seqüência 6 apresenta um valor de TR igual a 0 . TR é uma variável discreta que assume valores inteiros positivos ou nulo. A uma série de 200 sequiências executadas numa sessão experimental corresponde uma série de 200 valores de TR (um para cada seqüência emitida).

O segundo conceito que convém definir é o conceito de sequiência critério. Seqüência critério é aquela que apresenta um valor de TR igual ou superior a $n$, quando a contingência em vigor estabelece que somente poderão ser reforçadas as sequiências que apresentarem um valor de TR igual ou superior a $n$ (No esquema lag- $n$, a emissão de uma sequiência critério é necessariamente reforçada).

O terceiro e último conceito necessário é o de probabilidade condicional de reforçamento, $(\mathrm{PCr})$ definida como a probabilidade de ser liberado o reforço, dado que o sujeito tenha emitido uma seqüência critério (No esquema lag-n, essa probabilidade é sempre igual a $100 \%$ ).

Machado (1989) dispôs o conjunto dos 20 últimos TRs em ordem crescente, e o componente ordinal $m$, relativo ao percentil $\mathrm{P}$, foi computado sobre essa série, tal que $m=$ 20P/100. Se se tratasse do $70^{\circ}$ percentil, por exemplo, $m$ era igual a 14, isto é, o décimo quarto valor da série $\left(\mathrm{k}_{14}\right)$ era tomado como referência para critério. Todas as sequiências que apresentassem um valor de TR superior a $\mathrm{k}_{14}$ (seqüências critério) eram reforçadas segundo o valor de probabilidade condicional de reforçamento (a probabilidade de serem reforçadas era igual a PCr). As sequiências que apresentassem um valor de TR igual ou inferior a $\mathrm{k}_{14}$ não eram reforçadas.

Ao adotar esse procedimento, pressupôs o autor que a probabilidade de que ocorresse cada um dos valores da série (isto é, a probabilidade de que fosse emitida uma sequiência cujo valor de TR fosse igual a $\mathrm{k}_{1}$, ou $\mathrm{k}_{2}$, ou...ou $\mathrm{k}_{20}$ ) aproximava-se de $1 / 20$. Há seis valores iguais ou superiores a $\mathrm{k}_{14}$, pelo que se pode inferir que a probabilidade de que fosse emitida uma sequiência cujo valor de TR excedesse o valor de $\mathrm{k}_{14}$ mantinha-se sempre em torno de $30 \%$. De forma mais geral, a probabilidade de emissão de uma sequiência reforçável (PSc) foi sempre igual ou ligeiramente inferior ao valor complementar do percentil estipulado (se, por exemplo, foi computado o $60^{\circ}$ percentil, a probabilidade de emissão de uma seqüência reforçável esteve sempre à volta dos $40 \%)$. 
Em Machado (1989), o valor do percentil foi manipulado e seus efeitos sobre a aleatoriedade medidos. A diferentes grupos foram impostos os valores percentis $25 \%$ (grupo 1), $50 \%$ (grupo 2) e $75 \%$ (grupo 3). Note-se que, embora o valor do percentil tenha sido manipulado e, portanto, indiretamente também o tenha sido a probabilidade de emissão de seqüências reforçáveis, a probabilidade global de reforçamento (PGr), estipulada a priori pelo experimentador, manteve-se constante e igual ao produto (PSc) x (Pcr). Assim, uma $\mathrm{PGr}=0,3$ pôde ser obtida, por exemplo, com PSc $=0,3\left(70^{\circ}\right.$ percentil $)$ e $\mathrm{PCr}=1$ ou $\mathrm{PSc}=0,5\left(50^{\circ}\right.$ percentil $)$ e $\mathrm{PCr}=0,6$ ou ainda, $\mathrm{PSc}=0,75\left(25^{\circ}\right.$ percentil $)$ e $\mathrm{PCr}=0,4$ e assim com outros valores possíveis.

Em tese, portanto, Machado exigiu, dos animais do grupo 2 , a emissão de sequiências cuja ocorrência era, no repertório desses animais, menos provável do que o era a ocorrência das seqüências que exigiu dos animais do grupo 1. O mesmo se pode afirmar do grupo 3 relativamente ao grupo 2 .

Note-se, além disso, que essas relações mantinham-se inalteradas, por mais que se alterassem os repertórios de cada animal, durante o experimento. A principal variável dependente foi o grau de aleatoriedade que apresentavam as diversas séries de seqüências, emitidas em cada sessão experimental.

Um índice estatístico, similar ao $U$ de Page e Neuringer (1985), constituiu a variável dependente de Machado (1989). Constatou o autor que o grau de aleatoriedade era tanto maior, quanto maior era o valor percentil a que estavam submetidos os animais. Assim os animais do grupo 3 apresentaram seqüências mais aleatórias que as apresentadas pelos animais do grupo 2, os quais apresentaram, por sua vez, seqüências mais aleatórias que as apresentadas pelos animais do grupo 1. Significa isso que, ao reforçar diferencialmente a emissão de determinadas seqüências de respostas, o grau de aleatoriedade obtido foi tanto maior, quanto menos provável era a emissão das seqüências a que, se emitidas, se seguiria a apresentação de reforços. Note-se ainda que, graças ao artifício adotado pelo pesquisador, a frequiência geral de reforçamento manteve-se praticamente a mesma, sob quaisquer condições. Podemos, portanto, atribuir a emissão das seqüências aleatórias ao procedimento dos percentis.

\section{Seleção Dependente da Freqüência}

Machado (1992) investigou os efeitos do reforçamento diferencial sobre o comportamento de gerar seqüências aleatórias. Seu procedimento exato foi este: Machado treinou pombos a responderem a duas chaves. Situavam-se as chaves, uma ao lado da outra, no interior de uma caixa experimental. A apresentação do reforço era contingente a que os animais respondessem às chaves direita (D) e esquerda (E). As sequiências assim produzidas apresentavam dois caracteres, $E$ e $D$.

As probabilidades de que fossem reforçadas as respostas a cada uma delas eram inicialmente função da propor- ção em que se encontrassem no conjunto das $m$ últimas respostas emitidas (o valor de $m$ foi manipulado, assumindo os valores 20, 40 e 80). À medida que as proporções (a proporção de bicadas à chave direita e a proporção de bicadas à chave esquerda) se afastavam de $50 \%$, a resposta menos freqüente era seguida do reforço com maior probabilidade, o inverso ocorrendo à mais freqüente.

Note-se que, diferentemente do que ocorria em Page e Neuringer (1985), em que o reforço só era apresentado, quando o era, ao final da emissão da quarta e última resposta constituinte da sequiência, em Machado (1992), o reforço podia ser liberado ao final de qualquer resposta individual.

O resultado obtido foi uma seqüência comportamental altamente estereotipada de simples alternações entre respostas à chave direita e respostas à chave esquerda. Os pombos estiveram muito próximos de emitir seqüências como DEDEDE....

Numa fase posterior, a apresentação do reforço tornouse contingente às proporções em que se apresentavam os pares de respostas consecutivas. Sendo duas as respostas discretas possíveis (à chave direita e à chave esquerda), havia quatro pares possíveis (DD, DE, ED, e EE). Se a resposta corrente foi $\mathrm{D}$ e a resposta imediatamente anterior foi $\mathrm{E}$, por exemplo, o critério de reforçamento da resposta corrente (D) baseou-se na proporção em que o par E-D se havia apresentado, no conjunto das $m$ respostas emitidas até então. O mesmo critério aplicou-se aos outros três pares possíveis. Assim, à medida que as proporções (proporção de pares EE, proporção de pares ED, proporção de pares $\mathrm{DE}$, proporção de pares $\mathrm{DD})$ se afastavam de $25 \%$, a resposta que completasse o par menos freqüente era seguida do reforço com maior probabilidade, o inverso ocorrendo àquelas que compusessem os pares mais freqüentes.

$\mathrm{O}$ resultado mostrou que alguns sujeitos apresentaram um comportamento estereotipado, ainda que mais complexo, de alternações duplas entre as chaves, algo próximo disto: DDEEDDEE.... Esse padrão seqüencial contém os quatro pares possíveis (DD, DE, ED, e EE) em iguais proporções.

Outros sujeitos apresentaram, no entanto, um comportamento próximo ao que se havia de esperar, se as seqüências houvessem sido produzidas aleatoriamente. $\mathrm{O}$ autor sugere então que um passo a mais na exigência, ou seja, a seleção de tercetos de respostas consecutivas menos freqüentes geraria nos animais um comportamento idêntico ao que obteríamos, se, por exemplo, a seqüência de caracteres $E$ e $D$ houvessem sido geradas por sucessivos lançamentos de uma moeda não viciada. Índices de aleatoriedade constituíram também variáveis dependentes em Machado (1992).

Ao definir esse procedimento experimental, o autor inspirou-se num modelo de seleção cujos princípios foram bem estabelecidos pela biologia evolutiva, denominado seleção dependente da frequiência (Futuyma, 1986/1992). Na evolução biológica, esse mecanismo é o responsável pela seleção positiva de genes ou conjunto de genes presentes em 
baixas freqüências numa população. $\mathrm{O}$ valor adaptativo desses genes é função da freqüência relativa em que se encontram numa população. Assim, o seu valor adaptativo decresce, à medida que sua frequiência relativa cresce numa população. Tudo se passa como se a sua freqüência relativa constituísse um aspecto do meio que o seleciona. O produto final dessa seleção é uma situação de equilíbrio dinâmico, em que a frequiência relativa do gene em questão mantém-se constantemente em níveis intermediários.

O problema da intermitência, a que já aludimos, poderia ocorrer também nesse caso. Uma vez que as respostas eram seguidas de reforço, somente se satisfizessem os critérios de proporcionalidade acima descritos, houve provavelmente algumas delas a que não se seguiu a apresentação de reforço. Essa intermitência pode ter mesmo aumentado, quando, na segunda fase do experimento, tornaram-se mais exigentes os critérios de reforçamento.

Machado (1992) contornou o problema, lançando mão de um expediente que permitiu manter mais ou menos constante, num valor aproximado de $5 \%$, a proporção de respostas reforçadas (ou melhor, a probabilidade geral de reforçamento), durante todo o experimento. A probabilidade geral de reforçamento (PG) era a soma de duas probabilidades parciais: A probabilidade de que fosse reforçada a resposta à chave esquerda (PRE) e a probabilidade de que fosse reforçada a resposta à chave direita (PRD). PRE, por sua vez, era o produto de duas outras probabilidades: a probabilidade de que ocorresse uma resposta à chave esquerda $(\mathrm{PE})$ e a probabilidade de que houvesse apresentação de reforço, tendo ocorrido resposta à chave esquerda (PR/E). De forma análoga, PRD era o produto de duas outras probabilidades: a probabilidade de que ocorresse uma resposta à chave direita $(\mathrm{PD})$ e a probabilidade de que houvesse apresentação de reforço, tendo ocorrido resposta à chave direita (PR/D). Formalmente escrevemos: $\mathrm{PG}=(\mathrm{PE}) \mathrm{X}(\mathrm{PR} /$ $\mathrm{E})+(\mathrm{PD}) \mathrm{X}(\mathrm{PR} / \mathrm{D})$. Chamando $d$ à proporção de respostas à chave direita, computada para as $m$ últimas respostas emitidas (lembrando-se de que $d$ correspondia ao valor corrente de $\mathrm{PD}$, e seu complemento, $1-d$, correspondia ao valor corrente de PE), temos que Machado estabeleceu as seguintes condições de reforçamento: Se $d$ fosse menor que o quociente PG / (1 + PG), (PR/D) era igual a 1 e $(\mathrm{PR} / \mathrm{E})$ era igual a $(\mathrm{PG} \mathrm{X} d) /(1-d)$. Se $d$ fosse maior que o quociente $1 /(1+\mathrm{PG}),(\mathrm{PR} / \mathrm{D})$ era igual a $[\mathrm{PG} \mathrm{X}(1-d) / d] \mathrm{e}$ (PR/E) era igual a 1 . Se $d$ fosse maior que (ou igual ao) o quociente PG / ( $1+\mathrm{PG})$ e menor que (ou igual ao) o quociente $1 /(1+\mathrm{PG}),(\mathrm{PR} / \mathrm{D})$ era igual a $[\mathrm{PG} \mathrm{X}(1-d) / d] \mathrm{e}$ $(\mathrm{PR} / \mathrm{E})$ era igual a $(\mathrm{PG} \mathrm{X} d) /(1-d)$. Por essa forma, Machado alcançou que a proporção de respostas reforçadas se mantivesse sempre próxima aos 5\%, ainda que as probabilidades condicionais, PR/E e PR/D, flutuassem em função do desempenho dos animais.

Vimos que, ao contrário dos experimentos anteriormente mencionados, este estudo elegeu a resposta discreta para unidade reforçável. Os resultados de Machado (1992) mostraram, portanto, que também esse esquema pôde engendrar certo grau de aleatoriedade nas séries emitidas.

\section{Alternação}

As contingências que até aqui descrevemos exigem, ainda que indiretamente, que o animal alterne suas respostas entre os dois manipulanda. Isto é, exigem que o animal passe de uma a outra chave ou barra, um número mínimo de vezes. Contudo esses esquemas não estabelecem diretamente nenhuma contingência sobre essa variável. Poderia a emissão de sequiências aleatórias resultar do mero reforçamento diferencial da resposta de alternar entre as chaves ou barras? Isto é, poderia uma contingência dessa espécie produzir a emissão de sequiências aleatórias, ainda que não estabelecesse qualquer exigência quanto à freqüência recente em que vêm sendo emitidas certas respostas ou seqüências específicas?

Machado (1997) examinou essa hipótese. Esse pesquisador colocou sete pombos diante de duas chaves de bicar, alinhadas horizontalmente. A emissão de oito respostas consecutivas definia uma tentativa, ao final da qual poderia apresentar-se o reforço ou um time-out, segundo critérios que descreveremos em seguida. $\mathrm{O}$ autor conduziu três diferentes experimentos.

A proporção de diferentes sequiências constituiu a variável dependente. Esta proporção correspondia à razão $n u ́-$ mero de diferentes seqüências emitidas x 100\% / número total de seqüências emitidas.

No primeiro experimento, reforçaram-se diferencialmente seqüências de oito respostas consecutivas que apresentassem, ao menos, uma (grupo 1) ou duas (grupo 2) alternações entre as chaves de resposta (por exemplo, EEEEEEED: uma alternação, pois o animal passou de uma a outra chave uma única vez; EEEEEDEE: duas alternações, pois o animal passou de uma a outra chave por duas vezes). As emissões das sequiências eram sempre seguidas do reforço, desde que as sequiências exibissem o número mínimo de alternações. Os animais poderiam, portanto, ter acesso a todos os reforços disponíveis, emitindo uma única seqüência com o número mínimo de alternações (uma ou duas), no decurso de todo o experimento. Os dados colhidos mostraram que os animais exibiram um número médio de quatro alternações por sequiência, em ambos os grupos. A proporção média de diferentes sequiências emitidas pelos pombos, nas três sessões finais, ficou em aproximadamente $69 \%$.

No segundo experimento, Machado (1997) adotou procedimento análogo ao desenvolvido no primeiro caso, com os mesmos sujeitos experimentais. A diferença esteve em que valores distintos de probabilidade condicional de reforçamento foram associados a cada seqüência, segundo o número de alternações que a compunha. Foram os seguintes os valores de probabilidade condicional: zero e sete alternações, $3 \%$; uma e seis alternações, 20\%; duas e cinco alternações, $60 \%$; três e quatro alternações, $100 \%$. Os registros, para as seis sessões finais, revelaram que o número médio de alternações por seqüência sofreu um pequeno decréscimo, atingindo o valor aproximado de 3,5 alternações por sequiência. A proporção média de diferentes sequiências registrou igualmente um declínio de alguns pontos, ficando em torno de $61 \%$. 
Num terceiro experimento, Machado (1997) replicou o procedimento reportado em Page e Neuringer (1985). Utilizando-se de sujeitos experimentalmente ingênuos, Machado adotou um delineamento ABA. Em A, foi instaurado um esquema lag-25. Em B, foi estabelecido um esquema selfyoked. Ou seja, em B, foram apresentadas aos sujeitos suas próprias distribuições de reforços, por tentativa, obtidas na primeira fase de vigência do esquema lag-25 (os sujeitos foram emparelhados a eles mesmos). Os resultados mostraram que, nas seis sessões finais, os sujeitos do experimento três apresentaram porcentagens médias de diferentes sequiências de $64 \%$ e $74 \%$, médias (referentes às seis sessões finais) relativas à primeira e segunda fases de lag-25, respectivamente. No esquema self-yoked, essa média desceu ao valor aproximado de $30 \%$. O número médio de alternações por seqüência atingiu uma marca inferior a três alternações por seqüência, nas fases lag-25, e situou-se abaixo de uma alternação por sequiência, na fase self-yoked. As porcentagens médias de diferentes seqüências (64\% e 74\%) ficaram abaixo do índice obtido por Page e Neuringer (85\%). Machado sustenta que essa diferença pode dever-se ao fato de que os animais de Page e Neuringer passaram por um treino prévio em esquemas lag - $n$ de menores valores (lag-5, lag10 e lag-15, sucessivamente). Os animais ingênuos de Machado foram expostos diretamente à contingência lag-25.

Note-se que Machado (1997) instituiu aqui uma classe descritiva que diferia, num ponto fundamental, daquelas todas que descrevemos anteriormente (incluindo-se a contingência $l a g-n$ ): Em Machado, as respostas passadas dos pombos não entravam na composição do critério de reforçamento.

Os resultados de Machado (1997) mostraram que o reforçamento diferencial do número de alternações levou os pombos a emitirem grande número de sequiências diferentes. Um grau razoável de aleatoriedade pode ter sido alcançado.

\section{Considerações Finais}

De tudo o que acabamos de expor, podemos extrair alguns pontos principais. Temos, primeiramente, uma questão empírica muito bem definida: há uma ou mais contingências da forma $\mathrm{R}-\mathrm{S}$ que podem levar organismos a emitir sequiências aleatórias? Estudos que busquem resposta a essa questão podem, supomos, contribuir para a investigação daquilo a que, em linguagem ordinária, chamamos comportamento "criativo" ou "original" (Catania, 1998/1999; Page \& Neuringer, 1985).

As pesquisam nessa área enfrentam, contudo, duas dificuldades. Uma delas é de ordem metodológica e a ela já nos referimos anteriormente. A definição de aleatoriedade compreende os arranjos entre caracteres em todos os níveis (pares, tercetos, quartetos $\ldots n$ - tetos). As seqüências obtidas pelos pesquisadores são, no entanto, finitas. A análise há de, portanto, deter-se em algum nível de arranjo dos caracteres.
Há, ainda, sobre a dificuldade metodológica, uma dificuldade teórica no estudo do comportamento aleatório. Se chamamos "reforçadoras" àquelas consequiências que elevam a probabilidade de emissão das respostas específicas que as produziram, o reforçamento deveria sempre redundar em diminuição da diferença entre as respostas emitidas. O reforçamento deveria produzir, pois, uma maior estereotipia comportamental. Se o comportamento aleatório pode ser obtido por reforçamento diferencial, em contingências da forma $\mathrm{R}$ - S, que papel deveríamos atribuir ao procedimento de reforçar (Page \& Neuringer, 1985)? Leiase, a propósito, o seguinte comentário de Catania (1998/ 1999, p. 144):

Mas o reforço diferencial da novidade (originalidade) ou da variabilidade suscita algumas questões. Os reforços são produzidos por respostas individuais, contudo as propriedades como a novidade e a variabilidade não podem ser propriedades de respostas individuais. Elas somente podem ser propriedades de respostas no contexto de outras respostas que ocorreram antes. Uma resposta em particular pode ser variável no contexto de uma sequiência de respostas passadas e estereotipada no contexto de outra. Assim, o fato de que a novidade (originalidade) e a variabilidade podem ser diferencialmente reforçadas significa que os organismos são sensíveis a populações de respostas e de consequiências ao longo de extensos períodos de tempo, e não meramente a seqüências individuais resposta-estímulo.

O estudo do comportamento aleatório impõe, assim, desafios empíricos e teóricos. Supomos, contudo, ser esse um motivo mais a instigar aqueles que o queiram investigar, empirica ou teoricamente. Defendemos, portanto, que o comportamento aleatório pode, e talvez deva, tornar-se legítimo objeto de estudo de uma ciência do comportamento.

\section{Referências}

Antonitis, J.J. (1951). Response variability in the rat during conditioning, extintion, and reconditioning. Journal of Experimental Psychology, 42, 273-281.

Attneave, F. (1969). Applications of information theory to psychology: a summary of basic concepts, methods and results. New York: Holt-Dryden Book: Henry Holt.

Boren, J.J., Moerschbaecher, J.M. \& Whyte, A.A. (1978). Variability of response location on fixed-ratio and fixed-interval schedules of reinforcement. Journal of the Experimental Analysis of Behavior, 30, 63-67.

Catania, A.C. (1999). Aprendizagem: Comportamento, Linguagem e Cognição. (D.G. de Souza e cols., Trads.) 4 ed - Porto Alegre: Artes Médicas. (Trabalho original publicado em 1998)

Eckerman, D. \& Lanson, R. (1969). Variability of response location for pigeons responding under continuous reinforcement intermittent reinforcement, and extinction. Journal of the Experimental Analysis of Behavior, 12, 73-80.

Ferraro, D.P. \& Branch, K.H. (1968). Variability of response location during regular and partial reinforcement. Psychological Reports, 23, 1023-1031. 
Futuyma, D.J. (1992). Biologia Evolutiva; (M. de Vivo, Trad.). 2 ed. Ribeirão Preto: Sociedade Brasileira de Genética/CNPq. (Trabalho original publicado em 1986)

Machado, A. (1989). Operant conditioning of behavioral variability using percentil reinforcement schedule. Journal of the Experimental Analysis of Behavior, 52, 155-166.

Machado, A. (1992). Behavioral variability and frequency-dependent selection. Journal of the Experimental Analysis of Behavior, 58, 241-263.
Machado, A. (1997). Increasing the variability of response sequences in pigeons by adjusting the frequency of switching between two keys. Journal of the Experimental Analysis of Behavior, 68, 1-25.

Page, S. \& Neuringer, A. (1985). Variability is an operant. Journal of Experimental Psychology: Animal Behavior Processes, $11,429-452$.

Skinner, B.F. (1975) Contingências do Reforço. (Moreno, R., Trad.). Em: Skinner \& Piaget. São Paulo: Abril Cultural, col. Os Pensadores. (Trabalho original publicado em 1969)

Recebido em 24.05.2000

Primeira decisão editorial em 13.11.2000

Versão final em 10.01.2001

Aceito em 30.01.2001 